\title{
LSTM ile EEG Tabanlı Kimliklendirme Sistemi Tasarımı
}

\author{
${\text { Furkan Balci }{ }^{*} \text {, Zeki Oralhan }}^{2}$ \\ ${ }^{1}$ Nuh Naci Yazgan Üniversitesi, Mühendislik Fakültesi, Elektrik Elektronik Mühendisliği Bölümü, Kayseri, Türkiye (ORCID: 0000-0002-3160-1517) \\ ${ }^{2}$ Nuh Naci Yazgan Üniversitesi, Mühendislik Fakültesi, Elektrik Elektronik Mühendisliği Bölümü, Kayseri, Türkiye (ORCID: 0000-0003-2841-6115)
}

(Bu yayın 26-27 Haziran 2020 tarihinde HORA-2020 kongresinde sözlü olarak sunulmuştur.)

(DOI:10.31590/ejosat.779526)

\begin{abstract}
ATIF/REFERENCE: Balc1, F. \& Oralhan, Z (2020). LSTM ile EEG Tabanlı Kimliklendirme Sistemi Tasarımı. Avrupa Bilim ve Teknoloji Dergisi, (Special Issue), 135-141.

Öz

Tanımlama sistemleri son derece güvenilir kişisel veriler kullanılarak tasarlanmaktadır. Doğruluk oranı ve güvenilirlik bu sistemlerin en temel parametreleridir. Elektroensefalografi (EEG) sinyali zamana, içsel ve çevresel faktörlere bağlı olarak değişir. Yapılan çalışmalar sonucunda EEG sinyalinin tanımlama sistemlerinde kullanılabilirliği teyit edilmiştir. Çevresel etkiler en aza indirildiğinde vücut tarafından üretilen sinyallerin kişiselleştirilmiş sinyaller olduğu anlaşılmaktadır. Uzun Kısa Süreli Bellek (LSTM) yönteminin zaman serilerinde başarılı sonuçlar verdiği bilinmektedir. Bu çalışmada derin öğrenme tekniklerinden biri olan LSTM yöntemi kullanılarak bir tanımlama sistemi tasarlanmıştır. LSTM kullanılmadan once, EEG bazı işlemler ile frekans alt bileşenlerine bölünür. $\mathrm{Bu}$ ayrılan frekans alt bileşenlerinin korelasyon analizi ile delta dalgasının kullanılmasına karar verilmiştir. Hazırlanan system farklı koşullar altında incelenmiştir. Üç farklı eğitim serisi üzerinde 200 test yapılmıştır. En yüksek doğruluk oranı \% 89,5’tir. Ortalama doğruluk oranı \%86,292'dir. Hazırlanan system farklı koşullar altında çalışacak şekilde tasarlanmıştır. Sistem çeşitli optimizasyon algoritmalrı kullanılarak gelişime açıktır.
\end{abstract}

Anahtar Kelimeler: EEG, Kimliklendirme, Derin Öğrenme, LSTM

\section{EEG Based Identification System Design via LSTM}

\begin{abstract}
Identification systems are designed using highly reliable personal data. Accuracy rate and reliability are the most basic parameters of these systems. Electroencephalography (EEG) signal varies depending on time, internal and environmental factors. As a result of the studies, the usability of the EEG signal in identification systems has been confirmed. It is understood that the signals produced by the body are personalized signals when the environmental effects are minimized. Successful results are known in the time series of the Long-Short Term Memory (LSTM) method. In this study, an identification system was designed by using LSTM method, which is one of the deep learning techniques. Before the LSTM is used, the EEG is subdivided into frequency subcomponents through some operations. It was decided to use the delta wave with correlation analysis of these separated frequency subcomponents. The prepared system was examined under different conditions. A total of 200 tests were performed on 3 different training series. The highest accuracy rate is $89.5 \%$. The average accuracy rate is $86,292 \%$. The prepared system is designed to operate under different conditions. The system is open to development using various optimization algorithms.
\end{abstract}

Keywords: EEG, Identification, Deep Learning, LSTM

\section{Giriş}

Yapay zeka tekniklerinin uygulama alanları, günümüzde teknolojik gelişmelerdeki hızlı artışla donanım ve yazılım gelişmeleri sayesinde her geçen gün genişlemektedir. Öğrenme, sınıflandırma ve optimizasyon gibi konularda çok yüksek bir başarı oranına sahip olan bu teknikler, yüzyıllardır merak konusu olan insan beyninin yapısını modelleyerek tasarlanmıştır (Cireşan ve ark., 2012).

*Sorumlu Yazar: Nuh Naci Yazgan Üniversitesi, Mühendislik Fakültesi, Elektrik Elektronik Mühendisliği Bölümü, Kayseri, Türkiye, ORCID: 00000002-3160-1517, furkan.balci@hotmail.com.tr 
Çalışmalar sonucunda beynin hem uyanık hem de uyku durumunda sürekli bir elektriksel aktiviteye sahip olduğu gözlenmiştir. Bu biyoelektrik aktiviteye elektroensefalografi (EEG) sinyalleri adı verilmiştir (Jasper, 1958). EEG sinyalleri, EEG kaydedici yardımıyla beynin iç veya dış yüzeyinden elektrotlarla ölçülür (Fukushima, 1980). Ölçüm sırasında elektrotların yerleştirilmesine ilişkin düzenlemeler vardır. Günümüzde standart bir 10/20 elektrot düzenlemesi kullanılmaktadır. Kaydedilen bu EEG sinyalleri, hem zaman alanında hem de frekans alanında bileşenlere bölünerek analiz edildiğinde, EEG sinyallerinin anlamlı veriler sağladığı çalışmalarla keşfedilmiştir (Azevedo ve ark., 2009).

Günümüzde kişilerin güvenlikli bir şekilde tanınması için çeşitli yöntemler kullanılmaktadır. Bu yöntemler parmak izi, iris, ses, yüz gibi biyometrikleri kullanmaktadır. Fakat çeşitli yöntemler ile bu kişiye özgü biyometrik bilgiler kopyalanabilmektedir. Bu sebeple kimliklendirme sistemleri üzerinde yapılan çalışmalar için farklı biyometriklerin kullanılması amaçlanmaktadır. Elektroensefalografi işareti üzerinde yapılan çalışmalar ile bu işaretlerin anlamlı birçok bilgi verdiği gözlemlenmiştir. EEG işareti hem zaman bölgesinde hem de frekans bölgesinde incelenmiştir. EEG sinyalleri, güvenli ve kopyalamaya karşı koruma olduğu için bu alan için uygun bir sistem oluşturulmasına yardımcı olur. EEG sinyalleri, dışarıdan müdahale olmaksızın güvenli bir şekilde toplanan bir tür işaret olduğundan, kimlik tanıma sistemlerindeki kullanılabilirliği araştırılmaktadır. EEG sinyalinin, kişinin tanımlanması için görünmez özelliği nedeniyle çeşitli avantajları vardır. Öte yandan, karmaşık ve analiz edilmesi zordur. Bu işaret daha kolay analiz edilmesi için frekans alt bileşenlerine ayrılmıştır. Bu alt bileşenlerden en uygun olanı korelasyon analizi ve dalga çeşitlerinin bilinen özelliklerine göre seçilmiştir. Sistemde giriş olarak kullanılan delta dalgası ile kimlik tanımlaması yapılmaktadır. Bu çalışmanın amacı, EEG sinyalleri arasındaki fonksiyonel ilişkinin varlığını ve bu sinyallerin derin öğrenme algoritmalarında tanımlama alanında kullanımını araştırmaktır. Algoritma ağları, derin öğrenme algoritmasının parametrelerini sürekli güncelleyerek eğitilir. Farklı kanalların sayısı, eğitim verilerinin uzunluğu ve kullanılan örnekleme frekansları ile sinyallerin performansı test edilir. Bu makalenin bir sonucu olarak, kullanılacak eğitim verilerinin uzunluğu, kanal sayısı ve EEG ölçüm cihazının örnekleme frekansı ve önerilen yaklaşımın doğruluk değeri hakkında bilgilendirici olacaktır. Literatürde benzer çalışmalar bulunmaktadır. Bu çalışmalardan bazıları birden fazla dalga çeşidinin kombinlenmesi (Pomas ve Vinod, 2016) ile bazıları MAP yötemi (Marcel ve Millan, 2007) ile tasarlanmıştır. Bir diğer çalışmalarda ise RNN yapısı (Kumari ve Vaish, 2015) ve diğer yapay zeka yöntemleri (Sohankar ve ark., 2015. Altahat ve ark., 2015. Ashby ve ark., 2011) kullanılmıştır.

Bu makale şu şekilde organize edilmiştir: Bölüm 2'de materyal kısmında kullanılacak EEG veri setleri hakkında, metot kısmında yapılacak işlemlerin adımları hakkında bilgiler verilmektedir. Bölüm 3'te makalenin analiz sonuçları verilmektedir. Bölüm 4'te ise analiz sonuçlarına göre sonuç ve gelecek çalışmalar ile ilgili konular yer almaktadır.

\section{Materyal ve Metot}

\subsection{Materyal}

Bu makale kullanılmak üzere elektroensefalografi sinyaline ihtiyaç vardır. Bu işaret 8 denek üzerinden toplanmıştır. Toplanan EEG işaretleri hazırlanan algoritmanın farklı durumlardaki başarımlarının test edilmesi amacıyla farklı şekillerde kaydedilmiştir. Bu sebeple 3 farklı kayıt yapılmıştır. Bu kayıtlar iki ayrı kayıt cihazı üzerinden gerçekleştirilmiştir. Buradaki amaç farklı cihazlar ve bu cihazlara bağlı parametrelere (kanal sayısı, örnekleme frekansı vb.) göre tasarlanan LSTM yapısının her koşula uygun olup olmadığı görülmek istenmesidir. Yapılan kayıt işlemi için deneklere gözlerini kapatmaları ve gevşeme halinde olmaları istenmiştir (Florin ve Baillet, 2015). Daha sonra 14 kanallı 128 Hz örnekleme frekanslı EEG kayıt cihazı ve 64 kanallı 160 Hz örnekleme frekanslı EEG kayıt cihazı kullanmıştır. Kullanılan cihazlar $\mathrm{AgCl}$ (Gümüş klorür) elektrotlara sahiptir. Elektrotlar 10/20 elektrot düzenine göre yerleştirilmiştir. İlk EEG kayıt cihazı ile 2 farklı veri seti kaydedilmiştir. Bu veri setleri EEG-M ve EEG-S olarak adlandırılmıştır. EEG-M olarak adlandırılan veri seti için her kanalda 7000 örnek olacak şekilde üç defa kayıt alınmıştır. EEG-S olarak adlandırılan veri seti için her kanalda 7000 örnek olacak şekilde tek kayıt alınmıştır. İkinci EEG kayıt cihazı ile bir veri seti kaydedilmiştir. Bu veri seti EEG-C olarak adlandırılmıştır. EEG-C olarak adlandırılan veri seti için her kanalda 7000 örnek olacak şekilde tek kayıt alınmıştır.

\subsection{Metot}

Bu makale kapsamında LSTM yapısı kullanılarak EEG temelli hazırlanan kimliklendirme sistemi algoritması tasarlanmıştır. Tasarlanan bu algoritmada EEG veri setinin kullanılabilir hale gelmesi için bazı ön işlemlerden geçmesi gerekmektedir. Bu önişlemlerden sonra veri seti analiz için frekans alt bileşenlerine ayrıştırmak gerekmektedir. EEG işareti beş ana alt frekans bileşenine ayrıştırılmaktadır. En uygun dalganın seçilmesi için Pearson korelasyonları hesaplanmıştır. Seçilen en uygun dalga çeşidi daha sonra LSTM yapısına uygulanmıştır. Daha sonra LSTM yapısının çıktısı kullanıcı kimliklerine eşitlenmiştir. Yapılan bu işlem adımları şekil 1 'de görülmektedir. 


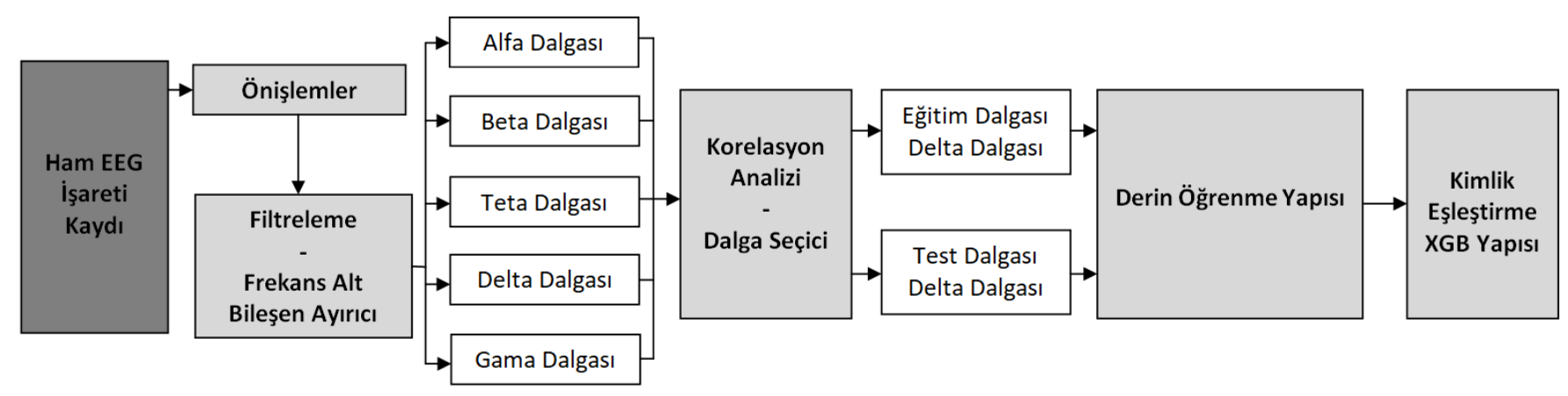

Şekil 1. Kimliklendirme Sistemi Blok Diyagramı

\subsection{1. Önişlemler}

Tasarlanan algoritma için ham EEG veri seti kullanılmadan önce bazı önişlemlerden geçmesi gerekmektedir. Bu önişlemlerden ilki EEG ölçüm cihazlarının temel olarak kullandığı DC ofset değerini kaldırmaktır. DC ofseti olarak adlandırılan gerilim değeri EEG ölçüm cihazlarının elektrotlarında sabir olarak eklenen bir gürültü bileşenidir. Bu yüzden ham EEG verisi üzerinden bu gürültü bileşeninin çıkarılması gerekmektedir. Normalleştirme yöntemi olarak z skoru ölçeklendirmesi kullanılmaktadır. Denklem 1'de görüldüğü üzere DC ofset çıkarımı ve işaretin normalleştirilmesi görülmektedir. Burada $\mathrm{O}_{\mathrm{f}}$, ofset değerini, $\mu$, $\mathrm{S}-\mathrm{O}_{\mathrm{f}}$ işleminin ortalamasını ve $\sigma$, standart sapmayı göstermektedir.

$$
S^{\prime}=\frac{\left(S-O_{f}\right)-\mu}{\sigma}
$$

\subsubsection{EEG Işsaretinin Analizi}

Genel kabul olarak EEG işaretleri beş farklı frekans bileşenine ayrılmaktadır. Önișlemlerden sonra elde edilen EEG veri seti frekans alt bileşenlerine ayrılacaktır. Bu alt bileşenler: Alfa, beta, delta, teta ve gama dalgalarıdır. Her dalga çeşidi farklı bir frekans aralığında salınım yapmaktadır. Her dalga çeşidinin dış dünyadan gelen etkenlere göre farkındalık düzeyi değişiklik göstermektedir. EEG verisi üzerinde kullanılması istenen dalganın kararlı olması istenmektedir. Bu sebeple kullanılacak dalga çeşidinin dış etkenlerden daha az etkilenmesi gerekmektedir. Dış etkenlerden etkilenme durumu farkındalık olarak adlandırılmaktadır (Azevedo ve ark., 2009).

Alfa dalgası 8 ile $13 \mathrm{~Hz}$ arasındadır. Bu dalga çeşidi insanlarda zihinsel hareketsizliğin en aza indirildiği durumda gözlemlenmektedir. Beta dalgası 13 ie $30 \mathrm{~Hz}$ arasındadır. Bu dalga çeşidi insanlarda bir şey üzerine düşünme ve bir şeye odaklanma anlarında gözlemlenmektdir. Teta dalgası 4 ile $8 \mathrm{~Hz}$ arasındadır. Bu dalga çeşidi genellikle bebeklerin derin uyku durumunda gözlemlenmektedir. Delta dalgası 0,5 ile $4 \mathrm{~Hz}$ arasındadır. Bu dalga çeşidi insanlarda gözlerin ani hareketinin olmadığ 1 ve rahatlama anında gözlemlenmektedir. Gama dalgası $30 \mathrm{~Hz}$ 'den büyüktür. Bu dalga çeşidi duygu geçişleri esnasında ve hafızada bulunan şeylerin hatırlanması esnasında gözlemlenmektedir (Azevedo ve ark., 2009).

Dalga çeşitlerinin genel özelliklerine bakılarak birçok sistem tasarımı ve araştırması yapılmaktadır. Bu özelliklerin referans alınması dışında korelasyon analizi de önemli bir ölçüttür. İşaret seçimi için korelasyon analizi kullanılmaktadır (Schalk ve Leuthardt, 2011. Mellinger ve ark., 2007). Bu sebeple üç verit seti üzerinde korelasyon analizi yapılmıştır. Bu korelasyon analizi sonucunda uygun dalga bileşeninin delta dalgası olduğu tespit edilmiştir. Ayrıca yapılan çalışmalar sonucunda delta dalgasının dinlenim durumunda ortaya çıkardığı işaretlerin vücudun içsel olarak ürettiği işaretler olduğu gözlemlenmiştir. Hem bu hipoteze hem de üç veri seti için yapılan korelasyon analizine göre sistem tasarımı için en uygun dalga çeşidinin delta dalgası olduğu kabul edilmiştir.

\subsubsection{LSTM Yapısi}

EEG sinyali kullanılarak kimlik tanımlama sistemi hazırlanması için derin öğrenme yapısı tasarlanmıştır. Sistemde kullanılacak derin öğrenme yapısı tekrarlayan sinir yapısının (RNN) bir çeşidi olan uzun kısa süreli bellek (LSTM) yapısıdır. RNN yapılarının temel özelliği zaman serileri üzerinde verdiği yüksek başarım oranlarıdır. Bu yapılar çıktı sadece o an giren değere bağlı olmayıp geçmiş verilere de bağlıdır. RNN temelli yaklaşımlar insan beyni gibi geçmiş verileri silmez. Klasik sinir ağı yapılarında ağırlıklandırma ayarı yapıldıktan sonra eski veriler silinir. Eski verilere bağlı serilerde ise bu durum en büyül dezavantajdır. RNN yapılarının geliştirilmesindeki amaç bu dezavantajın önüne geçmektir. RNN tabanlı yapılarda kullanılan veriler döngü tamamlanana kadar hafıza birimlerinde saklanır. Aslında temel olarak RNN yapısı klasik sinir ağlarına benzerdir. RNN yapısında ağlar çoğaltılarak belirli bir sırada dizilmektedir. Her ağın girişi önceki ağın çıkışına bağlıdır. RNN yapılarının bazı çeşitleri bulunmaktadır. Bu makale çalışmasında LSTM yapısı kullanılmıştır. LSTM yapısı EEG işareti gibi zamana göre değişim gösteren bir işarettir. RNN yapıları genelde tek katmanlı ağ yapısına sahiptir. LSTM yapıları ise dört katmanlı yapıya sahiptir. LSTM yapısında kapı olarak adlandırılan yapılar bulunmaktadır. Bu yapılar sinir hücresine bilgi ekleme ve çıkarma gibi görevleri yerine getirmektedir. Sinir ağlarında yaygın olarak kullanılan sigmoid fonksiyonu 0 ile 1 arasında değerlere sahiptir. Sinir ağı yapılarında bu fonksiyonun işlevi geçiş miktarını düzenlemektir. Bu kapıdan ilkine unutma kapısı denilmektedir. Bu kapı, önceki çıkış ile anlık giriş arasında bir analiz yapar ve 0 ile 1 arasında bir değer üretir. Oluşturulan değer 0 ise "bu durumu unut", 1 ise "bu durumu koru" anlamına gelir. Unutma kapısı $f_{t}$ ile gösterilir. Denklem 2'de unutma kapısını belirten eşitlik görülmektedir (Deng ve Yu, 2014). 


$$
f_{t}=\operatorname{sigmoid}\left(W_{f}\left[h_{t-1}, x_{t}\right]+b_{f}\right)
$$

Başka bir kapı katmanı giriş kapısıdır. Bu kapı yapısı hangi yeni değerlerin saklanacağına karar verir. Bu kapı işleminde hem sigmoid hem de tanh fonksiyonları kullanılmaktadır. Sigmoid yapı güncellenecek yeni değeri üretir ve tanh yapısı ise $\mathrm{C}_{\mathrm{tx}}$ ara değerini üretir. Denklem 3’te sigmoid fonksiyonunun, denklem 4'te tanh fonksiyonunun denklemi gösterilmektedir. Daha sonra bu denklemler birleştirilir (Deng ve Yu, 2014).

$$
\begin{gathered}
i_{t}=\operatorname{sigmoid}\left(W_{i}\left[h_{t-1}, x_{t}\right]+b_{i}\right) \\
C_{t x}=\tanh \left(W_{C}\left[h_{t-1}, x_{t}\right]+b_{c}\right)
\end{gathered}
$$

$i_{t}$ ve $C_{t x}$ değerleri kullanılarak eski verilerin bir sonraki hücreye aktarılmasını sağlayan $C_{t}$ üretilir. Denklem 5 'te eski veriler ve yeni girişler ile elde edilen mevcut veri denklemi $\mathrm{C}_{\mathrm{t}}$ 'yi gösterir.

$$
C_{t}=f_{t} * C_{t-1}+i_{t} * C_{t x}
$$

Bir sonraki adımda o hücrenin çıktısı hesaplanmalıdır. Bu hesaplanan çıktı bir sonraki hücrede kullanılmak üzere dallanmıştır. Hangi verilerin hücreden çıktı olarak kullanılacağına karar verilmesi gerekmektedir. Sigmoid işlevi bu kararı vermek için kullanılır. Denklem 6'da kullanılan bu işlevin eşitliği görülmektedir. Nihai hücre çıkışını elde etmek için tanh fonksiyonu kullanılarak sigmoid fonksiyonunun sonucunu -1 ve 1 arasında dönüştürülür. Denklem 7'de son hücre çıktısı denklemi gösterilmektedir. Şekil 2'de LSTM yapısının basit blok diyagramı görükmektedir (Deng ve Yu, 2014).

$$
\begin{gathered}
o_{t}=\operatorname{sigmoid}\left(W_{o}\left[h_{t-1}, x_{t}\right]+b_{o}\right) \\
h_{t}=o_{t} * \tanh \left(C_{t}\right)
\end{gathered}
$$

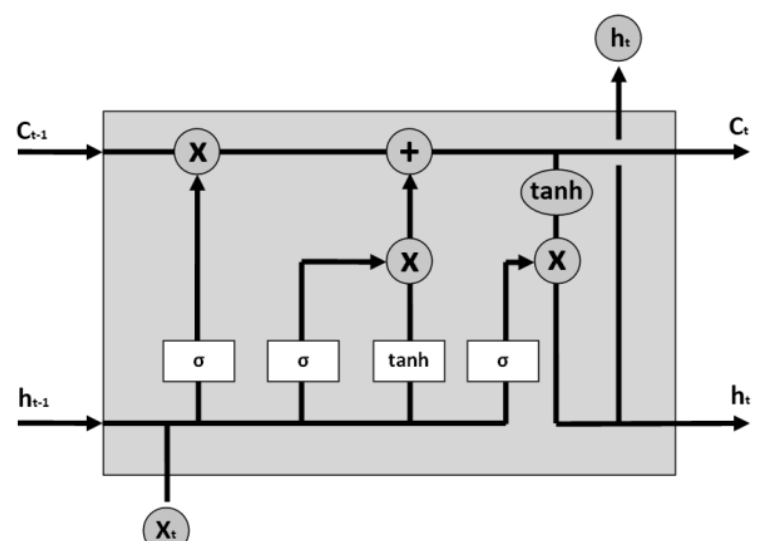

Şekil 2. LSTM Yapısının Blok Diyagramı

\subsubsection{Kimlik Eșitleme}

Yapay zeka temelli sınıflandırma çalışmalarında algoritma sonuçlarını sınıflandıran bazı sınıflandırıcı yapılar kullanılmaktadır. Bu yapılar sıklıkla öngörücü bir faktör olarak kullanılır. Derin öğrenme yapısının bir sonucu olarak elde edilen çıktı kullanıcı kimlikleriyle eşleştirilmelidir. Bu makale çalışmasında eşleştirme işlevi için Extreme Gradient Boosting sınıflandırıcısı kullanılmıştır.

Sınıflandırma amacıyla bu yapıda birçok ağaç vardır. Her ağaç bu yapıya giren verileri işler. Ağaç yapısı sinirsel ağ yapısına benzer. Bu yapı derin öğrenme algoritmasının çıktısı olan verileri ağılıklandırarak çalışır. Bu ve benzeri yöntemler iterasyon sayısı kadar çalışır. Bu iterasyon sayısındaki artış test süresinin artmasına neden olur. İterasyonların tamamlanması ile kimlik bilgileri elde edilir (Bashar ve ark., 2016).

Extreme Gradient Boosting sınıflandırıcı yapısının performansını artıran faktörler döngü sayısı ve kullanıcı etiket sayısıdır. Bu makalede optimum süre ve optimum doğruluk oranı için iterasyon sayısı 500 olarak belirlenmiştir.

\section{Araştırma Sonuçları ve Tartışma}

\section{1. Önişlem Sonuçları}

Kullanılacak olan ham EEG veri setleri üzerinde yapılacak olan DC ofset çıkarımı ve normalizasyon adımları sonrasında uygun dalga çeşidinin seçilmesi için korelasyon analizleri yapılmıştır. Yapılan analiz sonuçları tablo 1, tablo 2 ve tablo 3 'te görülmektedir. $\mathrm{Bu}$ tablolar incelendiğinde ortalama olarak en düşük korelasyon katsayısına sahip dalga çeşidinin delta olduğu görülmektedir. 


\begin{tabular}{lccccccccc}
\hline Dalga & Sub1 & Sub2 & Sub3 & Sub4 & Sub5 & Sub6 & Sub7 & Sub8 & Avg. \\
\hline Delta & 0,124 & 0,436 & 0,263 & 0,189 & 0,206 & 0,107 & 0,193 & 0,251 & $\mathbf{0 , 2 2 1}$ \\
Teta & 0,459 & 0,683 & 0,545 & 0,326 & 0,396 & 0,194 & 0,204 & 0,374 & 0,398 \\
Alfa & 0,392 & 0,642 & 0,645 & 0,389 & 0,275 & 0,334 & 0,296 & 0,463 & 0,429 \\
Beta & 0,256 & 0,492 & 0,331 & 0,316 & 0,274 & 0,321 & 0,245 & 0,454 & 0,336 \\
Gama & 0,539 & 0,678 & 0,545 & 0,378 & 0,541 & 0,656 & 0,436 & 0,524 & 0,537 \\
\hline
\end{tabular}

Tablo 1. EEG-M Veri Setinin Korelasyon Analizi

\begin{tabular}{lccccccccc}
\hline Dalga & Sub1 & Sub2 & Sub3 & Sub4 & Sub5 & Sub6 & Sub7 & Sub8 & Avg. \\
\hline Delta & 0,159 & 0,401 & 0,252 & 0,183 & 0,248 & 0,112 & 0,167 & 0,252 & $\mathbf{0 , 2 2 1}$ \\
Teta & 0,489 & 0,598 & 0,565 & 0,345 & 0,336 & 0,169 & 0,221 & 0,345 & 0,384 \\
Alfa & 0,352 & 0,702 & 0,586 & 0,390 & 0,379 & 0,245 & 0,263 & 0,412 & 0,416 \\
Beta & 0,296 & 0,542 & 0,387 & 0,385 & 0,329 & 0,365 & 0,247 & 0,468 & 0,377 \\
Gama & 0,503 & 0,679 & 0,592 & 0,453 & 0,598 & 0,621 & 0,321 & 0,654 & 0,553 \\
\hline
\end{tabular}

Tablo 2. EEG-S Veri Setinin Korelasyon Analizi

\begin{tabular}{lccccccccc}
\hline Dalga & Sub1 & Sub2 & Sub3 & Sub4 & Sub5 & Sub6 & Sub7 & Sub8 & Avg. \\
\hline Delta & 0,102 & 0,369 & 0,201 & 0,124 & 0,189 & 0,069 & 0,098 & 0,178 & $\mathbf{0 , 1 6 6}$ \\
Teta & 0,389 & 0,541 & 0,569 & 0,364 & 0,302 & 0,147 & 0,126 & 0,306 & 0,343 \\
Alfa & 0,302 & 0,625 & 0,624 & 0,328 & 0,319 & 0,197 & 0,308 & 0,329 & 0,379 \\
Beta & 0,429 & 0,597 & 0,512 & 0,379 & 0,538 & 0,561 & 0,345 & 0,615 & 0,497 \\
Gama & 0,478 & 0,616 & 0,468 & 0,347 & 0,498 & 0,635 & 0,411 & 0,498 & 0,493 \\
\hline
\end{tabular}

Tablo 3. EEG-C Veri Setinin Korelasyon Analizi

\subsection{Test Sonuçları}

EEG-M veri seti üzerinde 100 test yapılmıştır. EEG-S ve EEG-C veri setleri üzerinde her bir set için 50 test yapılmıştır. Yapılan testlerin sonucu olarak tablo 4 , tablo 5 ve tablo 6 'da karmaşıklık matrisleri görülmektedir. Tablolarda koyu olarak gösterilen değerler tahmin edilen kişi ile doğru kişinin eşleştiği doğru tahminleme işlemini göstermektedir. Aynı satırda bulunan diğer değerler ise yapılan yanlış eşleşme sonucunu vermektedir. Aynı satırda bulunan değerlerin toplamı test sayısını vermiştir.

\begin{tabular}{c|cccccccc}
\hline Tahmin & \multicolumn{7}{|c}{ Doğru Kişiler } \\
\cline { 2 - 9 } Edilen Kişiler & Kişi1 & Kişi2 & Kişi3 & Kişi4 & Kişi5 & Kişi6 & Kişi7 & Kişi8 \\
\hline Kişi1 & $\mathbf{8 9}$ & 2 & 0 & 1 & 3 & 0 & 3 & 2 \\
Kişi2 & 3 & $\mathbf{8 2}$ & 2 & 4 & 1 & 1 & 3 & 4 \\
Kişi3 & 1 & 0 & $\mathbf{9 1}$ & 2 & 1 & 0 & 2 & 3 \\
Kişi4 & 2 & 3 & 2 & $\mathbf{8 5}$ & 1 & 4 & 1 & 2 \\
Kişi5 & 4 & 2 & 3 & 1 & $\mathbf{8 0}$ & 3 & 6 & 1 \\
Kişi6 & 2 & 3 & 4 & 4 & 2 & $\mathbf{7 8}$ & 2 & 5 \\
Kişi7 & 1 & 4 & 2 & 0 & 2 & 3 & $\mathbf{8 7}$ & 1 \\
Kişi8 & 2 & 4 & 3 & 3 & 5 & 2 & 6 & $\mathbf{7 5}$ \\
\hline
\end{tabular}

Tablo 4. EEG-M Veri Setinin Karmaşıklık Matrisi

\begin{tabular}{c|cccccccc}
\hline Tahmin & \multicolumn{7}{|c}{ Doğru Kişiler } \\
\cline { 2 - 9 } Edilen Kişiler & Kişi1 & Kişi2 & Kişi3 & Kişi4 & Kişi5 & Kişi6 & Kişi7 & Kişi8 \\
\hline Kişi1 & $\mathbf{4 6}$ & 0 & 0 & 2 & 0 & 1 & 0 & 1 \\
Kişi2 & 2 & $\mathbf{4 4}$ & 0 & 1 & 0 & 2 & 1 & 0 \\
Kişi3 & 1 & 1 & $\mathbf{4 5}$ & 0 & 1 & 0 & 2 & 1 \\
Kişi4 & 2 & 2 & 1 & $\mathbf{4 0}$ & 2 & 1 & 0 & 2 \\
Kişi5 & 0 & 1 & 0 & 2 & $\mathbf{4 2}$ & 1 & 2 & 2 \\
Kişi6 & 2 & 1 & 1 & 2 & 2 & $\mathbf{4 1}$ & 0 & 1 \\
Kişi7 & 0 & 0 & 1 & 1 & 0 & 1 & $\mathbf{4 7}$ & 0 \\
Kişi8 & 1 & 3 & 2 & 0 & 1 & 2 & 2 & $\mathbf{3 9}$ \\
\hline
\end{tabular}




\begin{tabular}{c|cccccccc}
\hline Tahmin & \multicolumn{7}{|c}{ Doğru Kişiler } \\
\cline { 2 - 8 } Edilen Kişiler & Kişi1 & Kişi2 & Kişi3 & Kişi4 & Kişi5 & Kişi6 & Kişi7 & Kişi8 \\
\hline Kişi1 & $\mathbf{4 7}$ & 0 & 0 & 0 & 1 & 0 & 1 & 1 \\
Kişi2 & 1 & $\mathbf{4 4}$ & 1 & 0 & 0 & 2 & 1 & 1 \\
Kişi3 & 1 & 2 & $\mathbf{4 3}$ & 2 & 1 & 1 & 0 & 0 \\
Kişi4 & 0 & 0 & 1 & $\mathbf{4 5}$ & 1 & 0 & 2 & 1 \\
Kişi5 & 1 & 2 & 0 & 1 & $\mathbf{4 3}$ & 2 & 1 & 0 \\
Kişi6 & 0 & 1 & 1 & 0 & 1 & $\mathbf{4 5}$ & 0 & 2 \\
Kişi7 & 0 & 0 & 1 & 1 & 2 & 0 & $\mathbf{4 6}$ & 0 \\
Kişi8 & 1 & 0 & 1 & 0 & 0 & 2 & 1 & $\mathbf{4 5}$ \\
\hline
\end{tabular}

Tablo 6. EEG-C Veri Setinin Karmaşılklk Matrisi

\subsection{Tartışma}

$\mathrm{Bu}$ çalışmada elde edilen sonuçlar bazı değerlendirme yöntemleri kullanılarak anlamlı hale getirilmelidir. Makalenin değerlendirilmesi çeşitli koşullara göre karmaşıklık matrisi yardımıyla hesaplanan doğruluk, duyarlılık ve F1 skoru gibi yaygın olarak kullanılan değerlendirme araçları kullanılarak yapılmıştır. Tablo 7'de bu değerlendirme sonuçları görülmektedir.

\begin{tabular}{|c|c|c|c|c|c|c|c|c|c|c|}
\hline & & Kişi1 & Kişi2 & Kişi3 & Kişi4 & Kişi5 & Kişi6 & Kişi7 & Kişi8 & Ort. \\
\hline \multirow{3}{*}{\begin{tabular}{l}
$\sum_{0}$ \\
0 \\
\multicolumn{1}{|c|}{} \\
\end{tabular}} & Doğruluk & 0,89 & 0,82 & 0,91 & 0,85 & 0,80 & 0,78 & 0,87 & 0,75 & 0,834 \\
\hline & Duyarlılık & 0,856 & 0,82 & 0,851 & 0,85 & 0,842 & 0,857 & 0,791 & 0,806 & 0,834 \\
\hline & F1 Skoru & 0,873 & 0,82 & 0,88 & 0,85 & 0,821 & 0,817 & 0,829 & 0,777 & 0,833 \\
\hline \multirow{3}{*}{ 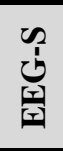 } & Doğruluk & 0,92 & 0,88 & 0,90 & 0,80 & 0,84 & 0,82 & 0,94 & 0,78 & $\overline{0,86}$ \\
\hline & Duyarlılık & 0,852 & 0,846 & 0,90 & 0,833 & 0,875 & 0,837 & 0,87 & 0,848 & 0,858 \\
\hline & F1 Skoru & 0,885 & 0,863 & 0,90 & 0,816 & 0,857 & 0,828 & 0,904 & 0,813 & 0,858 \\
\hline \multirow{3}{*}{ 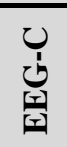 } & Doğruluk & 0,94 & 0,88 & 0,86 & 0,90 & 0,86 & 0,90 & 0,92 & 0,90 & $\overline{0,895}$ \\
\hline & Duyarlılık & 0,922 & 0,898 & 0,896 & 0,918 & 0,878 & 0,865 & 0,885 & 0,90 & 0,895 \\
\hline & F1 Skoru & 0,931 & 0,889 & 0,878 & 0,909 & 0,869 & 0,882 & 0,902 & 0,90 & 0,895 \\
\hline
\end{tabular}

Tablo 7. EEG-M, EEG-S ve EEG-C Veri Setlerinin Doğruluk, Duyarlılık ve F1 Skoru Sonuçları

Tablo 4'te görüldüğü gibi, EEG-M veri setindeki her bir denek için 100 test yapıldı. EEG-M veri seti için her bir denekten 21.000 örnek alınmıştır. Tablo 5 'te görüldüğü gibi, EEG-S veri setindeki her bir denek için 50 test yapıldı. EEG-S veri seti için her bir denekten 7.000 örnek alınmıştır. EEG-M ve EEG-S veri setleri üzerinde yapılan çalışmalarda kanal sayısı ve örnekleme frekansı aynıdır. Ancak, eğitim verilerinin uzunluğu ve test sayısı farklıdır. EEG-S ve EEG-C veri setleri üzerinde yapılan çalışmalarda, eğitim verilerinin uzunluğu ve test sayısı aynısı. Ancak, kanal sayısı ve örnekleme frekansı farklıdır. Bu nedenle, bu üç test çalışmaları karşılaştırıldığında, eğitim verilerinin uzunluğunun, örnekleme frekansının ve kanal sayısının doğruluk üzerindeki etkisi tablo 7'de görülmektedir. Tablo 6'da görüldüğü gibi, EEG-C veri setindeki her bir denek için 50 test yapıldı. EEG-C veri seti için her bir denekten 5.000 örnek alınmıştır. EEG-M ve EEG-S veri setleri üzerinde yapılan araştırmanın sonucu kullanılan eğitim setinin uzunluğunun doğruluk, duyarlılık ve F1 skoruna etkisi görülmektedir. EEG-S ve EEG-C veri setleri üzerinde yapılan araştırmanın sonucu kullanılan veri setlerinin örnekleme frekansı ve kanal sayısının doğruluk, duyarlılık ve F1 skoruna etkisi görülmektedir. EEGM veri seti üzerinde yapılan test sonuçlarının genel hata oranı \%83,375'tir. EEG-S veri seti üzerinde yapılan test sonuçlarının genel hata oranı \%86'dır. EEG-C veri seti üzerinde yapılan test sonuçlarının genel hata oranı \%89,5'tir. Bu sonuçlar göz önünde bulundurulduğunda tasarlanan sistemin yapısında kullanılacak olan EEG verisinin kanal sayısının ve örnekleme frekansının fazla olması doğruluk oranında artı̧̧a sebep olmaktadır.

Doğruluk, sağlamlık ve uygulanabilirlik gibi performans kriterleri analiz edilmelidir. En yeni tanımlama sistemleri, doğruluk kriterlerinde $\% 80$ ile\% 98 arasında sonuç vermektedir. Bu, birçok pratik uygulama için yeterli görünse bile geliştirilmesi gereken bir durumdur. Tablo 7 incelendiğinde, EEG-M ve EEG-S verileri üzerindeki test sonuçlarına göre; EEG-S verilerinin test değerlerinin doğruluğu daha yüksekti. Bu durumun ana nedeni artan test sayısının doğruluk üzerindeki etkisinin negatif olmasıdır. Yine aynı tablo incelendiğinde, EEG-C verilerinin test sonuçlarının doğruluğunun EEG-S ve EEG-C verileri arasındaki test sonuçlarına göre daha yüksek olduğu görülmektedir. Bu durumun ana nedeni, artan kanal sayısı ve örnekleme frekansı ile çözünürlüğü artırarak doğruluk üzerinde olumlu bir etkiye sahip olmasıdır.

Pratik senaryolarda ve gerçek dünya kullanımında, tanımlama sistemlerinin birden çok deneme tabanlı sisteme sahip olması gerekir. Sistemi eğitmek için kullanılan veriler kullanıcıyı tanımlamak için farklı test verileri içermelidir (Bashar ve ark., 2016). Örneğin, kişinin EEG kaydı elde edildikten sonra elektrotlar kişiden ayrılmalı ve tekrar yerleştirilmelidir. Çünkü bir sonraki ölçümde yaşanabilecek milimetre kaymalarına tolerans istenmektedir. Bu nedenle, sistemi tasarlarken ve eğitim verileri toplarken, eğitim verileri ile test verileri arasındaki farkındalık göz önünde bulundurulmalıdır. 


\section{Sonuç}

EEG sinyalinin kullanım alanları günden güne artmaktadır. Kimliklendirme sistemlerinin tasarımında EEG sinyalinin kullanılması son yıllarda araştırılan bir konudur. Bu makale çalışmasında otomatik olarak kimlik tanımlaması yapan bir sistem tasarımı gerçekleştirilmiştir. Yapılan bu çalışma üç ayrı veri seti üzerinde değerlendirilerek performans analizleri yapılmıştır. Yapılan analizlerin sonuçları 1şı̆̆ında yapılabilecek iyileştirmeler hakkında bilgiler edinilebilmiştir. Öncelikle sistemde kullanılacak EEG sinyalleri 8 deneğin katılımıyla kaydedilmiştir. EEG sinyali frekans alt bileşenlerine ayrılmıştır. Korelasyon ve dalga analizlerine göre delta dalgası sistem için en uygun dalga çeşidi olarak seçilmiştir. Delta dalgası kullanılarak sistemin çalışması daha kararlı hale getirilmiştir. Veri setlerinde bulunan verilerin \%62,5'luk kısmı eğitim verisi olarak kullanılmıştır. Daha sonra kalan veriler test verisi olarak kullanılmıştır. Ağırlıklandırma işlemini barındıran LSTM yapılarından sonra üretilen çıktı XGB yapısına girerek kimlik etiketlerinde eşleştirme işlemi yapılmaktadır. Kullanılan üç veri setinin farklı kanal sayısı, örnekleme frekansı, kayıt sayısı gibi parametrelere sahip olması yapılan test sonuçları ile sistem için uygun veri ölçümü hakkında bilgi elde edilmiştir. Tasarlanan LSTM algoritmasının en yüksek doğruluk oranı $\% 89,5$ ve ortalama doğruluk oranı $\% 86,292$ 'dir.

Gelecekte yapılacak çalışmalar için bu makale çalışması ön adımların atılmasını sağlamaktadır. EEG sinyalleri sağlıklı bireyler için yaşa göre değişim göstermektedir. Bu sorunun çözülmesi için zamanla ölçüm yapan otomatik bir sistem tasarımı yapılması amaçlanmaktadır. Bu sorunun yanında eğitim süresinin uzunluğu da önemli bir problem oluşturmaktadır. Bu sorun ise optimizasyon çalışmaları ile verinin düzenlenmesi ile aşılması amaçlanmaktadır. Hata oranının azaltılarak sistemin daha kararlı şekilde tasarlanması da bu amaçların temel hedefidir.

\section{Kaynakça}

Altahat, S., Che, G., Tran, D., Ma, W., 2015. Analysing the Robust EEG Channel Set for Person Authentication. International Conference on Neural Information Processing. Springer: 162-173.

Ashby, C., Bhatia, A., Tenore, F., Vogelstein, J., 2011. Low-cost electroencephalogram (EEG) based authentication. In Neural Engineering (NER). 2011 5th International IEEE/EMBS Conference. IEEE: 442-445.

Azevedo, F. A., Carvalho, L. R., Grinberg, L. T., Farfel, J. M., Ferretti, R. E., Leite, R. E., Herculano-Houzel, S., 2009. Equal numbers of neuronal and nonneuronal cells make the human brain an isometrically scaled-up primate brain. Journal of Comparative Neurology, 513(5): 532-541.

Bashar, K., Chiaki, I., Yoshida, H., 2016. Human identification from brain EEG signals using advanced machine learning method EEG-based biometrics. Biomedical Engineering and Sciences (IECBES), 2016 IEEE EMBS Conference. IEEE: 475-479.

Cireşan, D., Meier, U., Schmidhuber, J., 2012. Multi-column Deep Neural Networks for Image Classification. Computer Vision and Pattern Recognition: 3642-3649.

Deng. L., Yu, D., 2014. Deep Learning Methods and Applications. Foundations and Trends Signal Processing, (7): 198-250.

Florin, E., \& Baillet, S. (2015). The brain's resting-state activity is shaped by synchronized cross-frequency coupling of neural oscillations. NeuroImage, 111, 26-35. doi:https://doi.org/10.1016/j.neuroimage.2015.01.054

Fukushima, K., 1980. Neocognitrion: a self organizing neural network model for a mechanism of pattern recognition unaffected by shift in position. Biol. Cybern. 36 (4): 193-202.

Jasper, H., 1958. Report of the committee on methods of clinical examination in electroencephalography. Electroencephalography and Clinical Neurophysiology, 10: 370-375.

Kumari, P., Vaish, A., 2015. Brainwave based user identification system: A pilot study in robotics environment. Robotics and Autonomous Systems 65: 15-23.

Marcel, S., Millan, J., 2007. Person authentication using brainwaves (EEG) and maximum a posteriori model adaptation. IEEE transactions on pattern analysis and machine intelligence 29(4).

Mellinger, J., Schalk, G., Braun, C., Preissl, H., Rosenstiel, W., Birbaumer, N., Kübler, A., 2007. An MEG-based brain-computer interface (BCI). Neuroimage, 36(3): 581-593.

Pomas, K., Vinod, P., 2016. Utilizing individual alpha frequency and delta band power in EEG based biometric recognition. Systems, Man, and Cybernetics (SMC), 2016 IEEE International Conference. IEEE, 004787-004791

Schalk, G., Leuthardt, E.C., 2011. Brain-computer interfaces using electrocorticographic signals. IEEE Reviews in Biomedical Engineering, 4: 140-154.

Sohankar, J., Sadeghi, K., Banerjee, A., Gupta, S., 2015. E-bias: A pervasive eeg-based identification andauthentication system. Proceedings of the 11th ACM Symposium on QoS and Security for Wireless and Mobile Networks. ACM: 165-172. 